\title{
ATLANTIC MERIDIONAL OVERTURNING CIRCULATION STABLE OVER THE LAST 150 YEARS
}

\author{
Albert Parker ${ }^{1}{ }^{1}$, Clifford Ollier ${ }^{2}{ }^{2}$ \\ ${ }^{1}$ Independent Scientist, Bundoora, Australia \\ ${ }^{2}$ School of Agriculture and Environment, University of Western Australia, Perth, Australia
}

Manuscript received: March 8, 2018

Revised version: July 7, 2019

\begin{abstract}
Parker A., Ollier C., 2019. Atlantic Meridional Overturning Circulation stable over the last 150 years. Quaestiones Geographicae 38(3), Bogucki Wydawnictwo Naukowe, Poznań, pp. 31-40. 3+2 figs.

ABSTRACT: The Atlantic Meridional Overturning Circulation (AMOC) describes the northward flow of warm, salty water in the upper layers, and the southward flow of colder water in the deep Atlantic layers. AMOC strength estimates at $41^{\circ} \mathrm{N}$ latitude based on satellite sea surface height (SSH), and ARGO ocean temperature, salinity and velocity, and finally the difference in between the absolute mean sea levels (MSL) of the tide gauges of The Battery, New York, $40.7^{\circ} \mathrm{N}$ latitude, and Brest, $48.3^{\circ} \mathrm{N}$ latitude. Results suggest that the AMOC has been minimally reducing but with a positive acceleration since 2002, has been marginally increasing but with a negative acceleration since 1993, and has not been reducing but only oscillating with clear periodicities up 18 years, 27 years and about 60 years since 1856.
\end{abstract}

KEY wORDS: sea level rise; sea level acceleration; Atlantic Meridional Overturning Circulation

Corresponding author: Albert Parker, albert.parker.2014@gmail.com

\section{Introduction}

The Atlantic Meridional Overturning Circulation (AMOC), is a circulation system characterized by a northward flowing warm, saline water in the upper layers of the Atlantic, a cooling and freshening of the water at higher northern latitudes of the Atlantic in the Nordic and Labrador Seas, and by a southward flowing colder water at depth (Kuhlbrodt et al. 2007). The AMOC is defined as the total, basin-wide, circulation in the latitude depth plane, as typically quantified by a meridional transport stream-function (Clark et al. 2002). There are discussions about the AMOC slowing down because of global warming. The major effect of an AMOC slowing down would be cooler winters and summers around the North
Atlantic, and increased sea level rise along the Atlantic coast of North American coast. Some scientists have linked disruptions to the AMOC with almost every possible change in weather patterns and explained the onset of the last ice age with a weakened AMOC. The disaster movie The Day After Tomorrow was based on the idea that disruption of the AMOC would lead to extreme weather events and an enormous drop in temperatures.

The RAPID project (2019) has monitored the AMOC at $26.5^{\circ} \mathrm{N}$ latitude since 2004 (Hirschi et al. 2003, Cunningham et al. 2007, Johns et al. 2011). The total transport time series are obtained by composing the transport through the Florida Straits, the Ekman transport, and the density driven transport obtained from the mooring data. A reduced pattern has been shown since 2004 . 
Other measurements have been proposed to represent the strength of the AMOC. Willis and Fu (2008), Willis (2010), Hobbs and Willis (2012) proposed satellite observations of sea surface height (SSH) along with temperature, salinity and velocity from profiling floats to estimate changes in the north-ward flowing, upper limb, of the AMOC at latitudes around $41^{\circ} \mathrm{N}$. This overturning had somewhat smaller seasonal and inter-annual variability than at lower latitudes. Since 1993, there has been no reduction of the AMOC, and since 2002 , the reduction has been minimal and easing. The $26.5^{\circ} \mathrm{N}$ latitude RAPID results, like the $41^{\circ} \mathrm{N}$ latitude SSH + ARGO results by Willis and $\mathrm{Fu}$ (2008), Willis (2010), Hobbs and Willis (2012), do not span a time window of enough length to assess the influence of natural variability. Multi-decadal natural variability (Lozier et al. 2010, Parker 2016, Parker, Ollier 2016,) weighs negatively on these estimations made with just few years of data.

Iyengar (2009) and Schlesinger and Ramankutty (1994) demonstrated that multi-decadal oscillations in rainfall and temperature of quasi-60 years. Chambers et al. (2012) showed a similar quasi-60-year oscillation in global mean sea level. Hence, many proxies have been proposed, and it is very likely that the AMOC also exhibits a multi-decadal variability. Based on a proxy, Caesar et al. (2018), claimed the AMOC has been weakening by around 15\% since the mid-twentieth century. They say this weakening is revealed by a characteristic spatial and seasonal sea-surface temperature fingerprint consisting of a pattern of cooling in the subpolar Atlantic Ocean and warming in the Gulf Stream region that is calibrated through an ensemble of model simulations from the CMIP5 project. Also based on a proxy, Thornalley et al. (2018) provide palaeo-oceanographic evidence that Labrador Sea deep convection and the AMOC have been anomalously weak over the past 150 years, compared with the preceding 1,500 years. Their reconstructions indicate that the transition occurred either as a predominantly abrupt shift towards the end of the Little Ice Age (LIA), or as a more gradual, continued decline over the past 150 years. They suggest that more likely enhanced freshwater fluxes from the Arctic and Nordic seas towards the end of the LIA weakened Labrador Sea convection and the AMOC. It is generally accepted that along the North-East coast of North America, sea levels are critically influenced by the strength of the AMOC (Levermann et al. 2005, Yin et al. 2009, Sallenger et al. 2012, Ezer et al. 2013, Boon 2012). It is popularly believed, that a reduction in the strength of the AMOC translates in an acceleration of the absolute sea levels along the North-East coast of North America. However, these sea levels have been oscillating, rather than accelerating, with periodicity up to quasi-60 years (Parker 2013). In contrast to the results of Caesar et al. (2018), the results provided by Parker (2016) and Parker and Ollier (2016), suggest stability over time windows up to 150 years before present based on the MSL recorded by the tide gauges of The Battery, New York and Brest corrected for absolute land subsidence. Inferred from mean absolute sea level, the AMOC has not changed strength since 1856 but only oscillated.

\section{Method}

The sea levels measured by a tide gauge are relative to the instrument. The instrument may be subjected to an even larger vertical motion of subsidence or uplift. If $\boldsymbol{y}_{i^{\prime}} i=1, \ldots, n$ are the relative mean sea levels measured by a tide gauge at the time $x_{\mathrm{i}^{\prime}} \mathrm{i}=1, \ldots, \mathrm{n}$, the relative rate of rise of the sea levels $v$ is usually computed as the slope of the linear regression:

$$
y=\mathrm{A}+v \times x .
$$

The relative sea level acceleration $\boldsymbol{a}$ is computed as twice the second order coefficient of the quadratic regression:

$$
y=\mathrm{A}+\mathrm{B} \times x+1 / 2 \times a \times x^{2} .
$$

If $y_{i}, i=1, \ldots, n$ are the positions of an antenna co-located with the tide gauge instrument at the time $x_{\mathrm{i}^{\prime}} \mathrm{i}=1, \ldots, \mathrm{n}$, the absolute uplift velocity $w$ is usually computed as the slope of the linear regression:

$$
y=\mathrm{A}+w \times x .
$$

The absolute rate of rise of the sea levels is then:

$$
u=v+w .
$$




\section{Sea level results}

The relative sea level rates of rise and accelerations are computed first. In the tide gauge of The Battery, New York, Latitude $40.7^{\circ} \mathrm{N}$, Longitude $74.013^{\circ} \mathrm{W}$, with date range January 1856 to December 2017, the relative sea levels (data from PSMSL 2019) have been rising at a rate of $v=$ $+2.848 \mathrm{~mm} \mathrm{yr}^{-2}$. subjected to an acceleration of $a$ $=+0.00851 \mathrm{~mm} \mathrm{yr}^{-2}$. With the same time window, January 1856 to December 2017, in the tide gauge of Brest, Latitude $48.383^{\circ} \mathrm{N}$, Longitude $4.495^{\circ} \mathrm{W}$, the relative sea levels (data from PSMSL) have been rising at a rate of $v=+1.335 \mathrm{~mm} \mathrm{yr}^{-1}$ subjected to a similar acceleration of $\boldsymbol{a}=+0.00994 \mathrm{~mm}$ $\mathrm{yr}^{-2}$. The difference between the relative rates of rise of The Battery, New York and Brest is +1.513 $\mathrm{mm} \mathrm{yr}^{-1}$. However, these are relative, and not absolute, rates of rise, and include the differential sinking of the instruments. The accelerations are very close each other, $a=+0.0094 \mathrm{~mm} \mathrm{yr}^{-2}$ and $a$ $=+0.0098 \mathrm{~mm} \mathrm{yr}^{-2}$, respectively, for The Battery, New York and Brest. The absolute rates of uplift or subsidence of the instrument are then computed (Appendix 1).

In the analysis by NGL (2019, Blewitt et al. 2016) IGS08 reference frame (NGL 2018), the Global Navigation Satellite Systems (GNSS) antenna close to the tide gauge of The Battery, New York (NYBP, $49 \mathrm{~m}$ ) shows a recent subsidence rate of $w=-2.150 \mathrm{~mm} \mathrm{yr}^{-1}$, while the GNSS antenna close to the tide gauge of Brest (BRST, 293 $\mathrm{m}$ ) shows a recent subsidence rate of $w=-0.640$ $\mathrm{mm} \mathrm{yr}^{-1}$. The absolute sea level rates of rise are finally computed. The absolute sea level rate of rise in The Battery, New York is therefore $\boldsymbol{u}=$ $+0.698 \mathrm{~mm} \mathrm{yr}^{-1}$ while the absolute sea level rate of rise in Brest is therefore $u=+0.695 \mathrm{~mm} \mathrm{yr}^{-1}$. Their difference is only $+0.003 \mathrm{~mm} \mathrm{yr}^{-1}$.

Figure 1.a presents the absolute MSL of The Battery, New York, while figure 1.b presents the absolute MSL of Brest, over the time window January 1856 to present. The gaps in the MSL records are filled by interpolating nearby years. Where gaps extend more than one year, a 60 years periodicity of the oscillations about the linear trend is enforced. The filling of the gaps is needed to produce a continuous time series, but it introduces uncertainties. With the gaps filled, the relative rates of rise of the sea levels are now $v=+2.834 \mathrm{~mm} \mathrm{yr}^{-1}$ in The Battery, New York and $v=+1.344 \mathrm{~mm} \mathrm{yr}^{-1}$ in Brest. With the gaps filled, the relative sea level accelerations are now $+0.0084 \mathrm{~mm} \mathrm{yr}^{-2}$ in The Battery, New York and $+0.0086 \mathrm{~mm} \mathrm{yr}^{-2}$ in Brest. The absolute sea level rate of rise in The Battery, New York reduces to $u=+0.684 \mathrm{~mm} \mathrm{yr}^{-1}$ while the absolute sea level rate of rise in Brest increases to $u=+0.704 \mathrm{~mm} \mathrm{yr}^{-1}$. Their difference becomes $-0.020 \mathrm{~mm} \mathrm{yr}^{-1}$ (negative). Figure 1.c presents the difference between the absolute MSL of The Battery, New York and Brest. This difference is reducing at a rate of

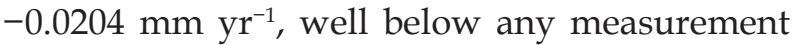
inaccuracy. This rate is subjected to a minimal positive acceleration, of $+0.00004 \mathrm{~mm} \mathrm{yr}^{-2}$.

\section{$41^{\circ} \mathrm{N}$ latitude AMOC SSH+ARGO and AMOC SSH results}

Estimations of the AMOC at $41^{\circ} \mathrm{N}$ latitude based on satellite sea surface height (SSH) show no critical slow-down since 1993 (Willis, Fu 2008, Willis 2010, Hobbs, Willis 2012). This AMOC SSH correlated very well with a more sophisticated AMOC, AMOC SSH+ARGO, based on this parameter plus the results of the ocean measurements from the ARGO profiling floats available since 2002 (Willis, Fu 2008, Willis 2010, Hobbs, Willis 2012). Both AMOC SSH and AMOC SSH+ARGO show relative stability since 2002 and 1993 (Parker 2016, Parker and Ollier 2016).

Figure 2 presents the latest $41^{\circ} \mathrm{N}$ latitude AMOC SSH+ARGO and AMOC results. This is an update of the results proposed in Willis and $\mathrm{Fu}$ (2008), Willis (2010), Hobbs and Willis (2012), Parker (2016), Parker and Ollier (2016). The overturning is defined as the sum of $0-1130$ $\mathrm{m}$ Geostrophic and Ekman transports. The time series represents three-month running averages. The AMOC sea surface height and ARGO (AMOC SSH+ARGO) is now updated to August 2018, courtesy of Josh Willis. The AMOC sea surface height (AMOC SSH) is now updated to October 2017, also courtesy of Josh Willis.

While there is certainly a diminishing trend, especially when starting from a peak, of the shortterm peaks and valleys oscillations, since 2005, the diminishing trend reduces over the 16 yearstime-window, since 2002, to only $-0.0572 \mathrm{~Sv}^{(\mathrm{a})} \mathrm{yr}^{-1}$.

(a) $\mathrm{Sv}$ - the transport units are Sverdrups, $1 \mathrm{~Sv}=10^{6} \mathrm{~m}^{3} \mathrm{~s}^{-1}$. 

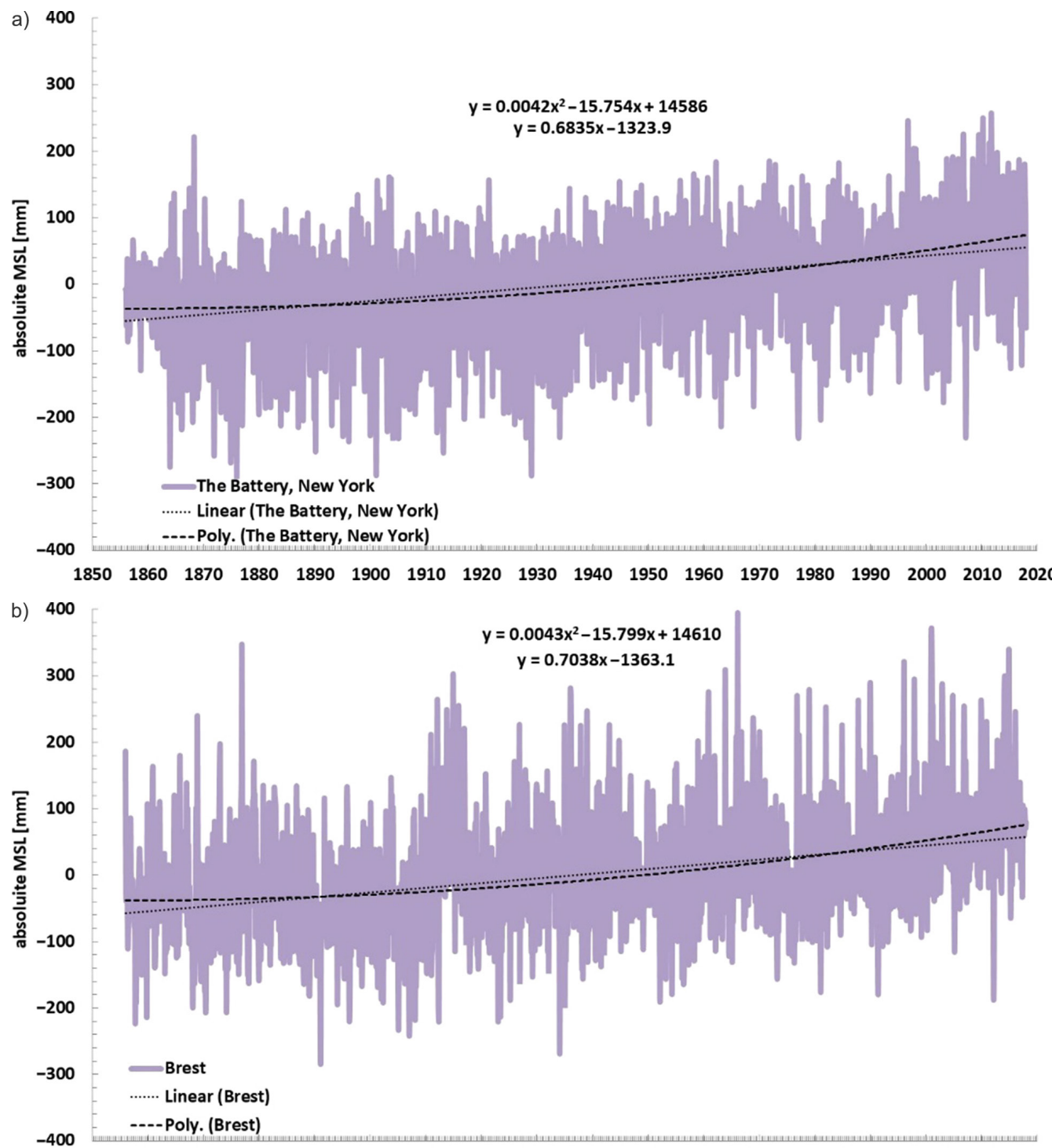

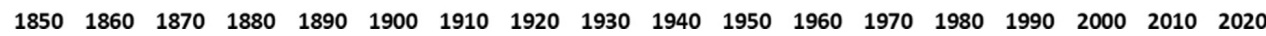

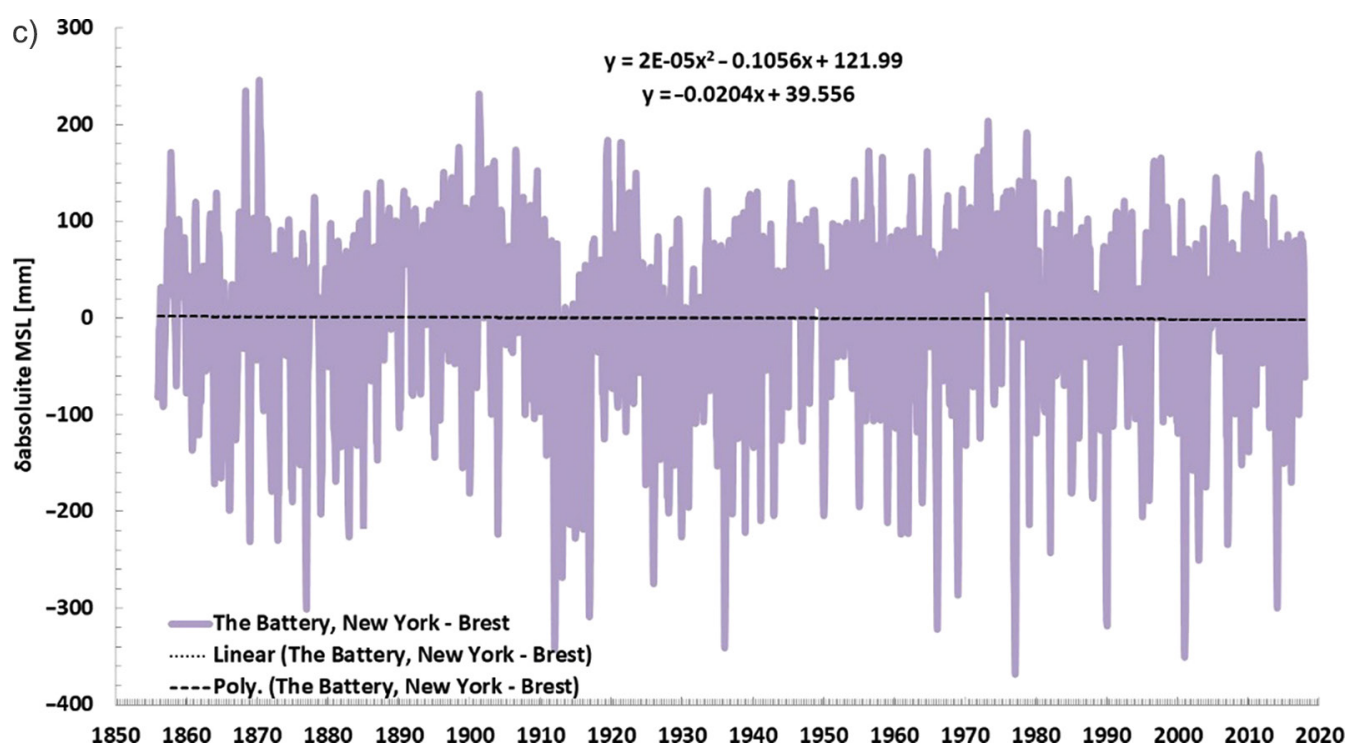

Fig. 1. Absolute mean sea levels in a) The Battery, New York and b) in Brest. Difference between the absolute mean sea levels in The Battery, New York and Brest (c). 
The acceleration is positive over the time window, $+0.0134 \mathrm{~Sv} \mathrm{yr}^{-2}$, demonstrating the small reduction of this AMOC is going to disappear. Since 1993, the $41^{\circ} \mathrm{N}$ latitude AMOC based on sea surface height (SSH) only measurements has been not reducing, but increasing, at a rate of $+0.0104 \mathrm{~Sv} \mathrm{yr}^{-1}$. The acceleration is now negative over this time window, $-0.0144 \mathrm{~Sv} \mathrm{yr}^{-2}$ demonstrating the small increase of this AMOC is also going to disappear. Trend and acceleration results are only marginally different from those proposed by Parker (2016) and Parker and Ollier (2016) based on a shorter time window, but also slightly different data sets.

It must be mentioned, that the latest AMOC SSH+ARGO of 2018 and AMOC SSH of 2017 differ from the AMOC SSH+ARGO and SSH of 2015 used in Parker (2016) and Parker and Ollier
(2016). The differences between the two results reflect changes in the data sets the computations are based on (Appendix 2).

All the climate data sets are unfortunately somewhat unreliable because past values have often been subjected to administrative corrections. This includes the satellite altimeter sea level height, the sea surface temperature, the temperature and the velocity and salinity of the oceans at different depths.

\section{MSL Proxy AMOC results}

If we accept the idea that a change of strength of the AMOC would translate into an acceleration of the sea levels along the East Coast of North
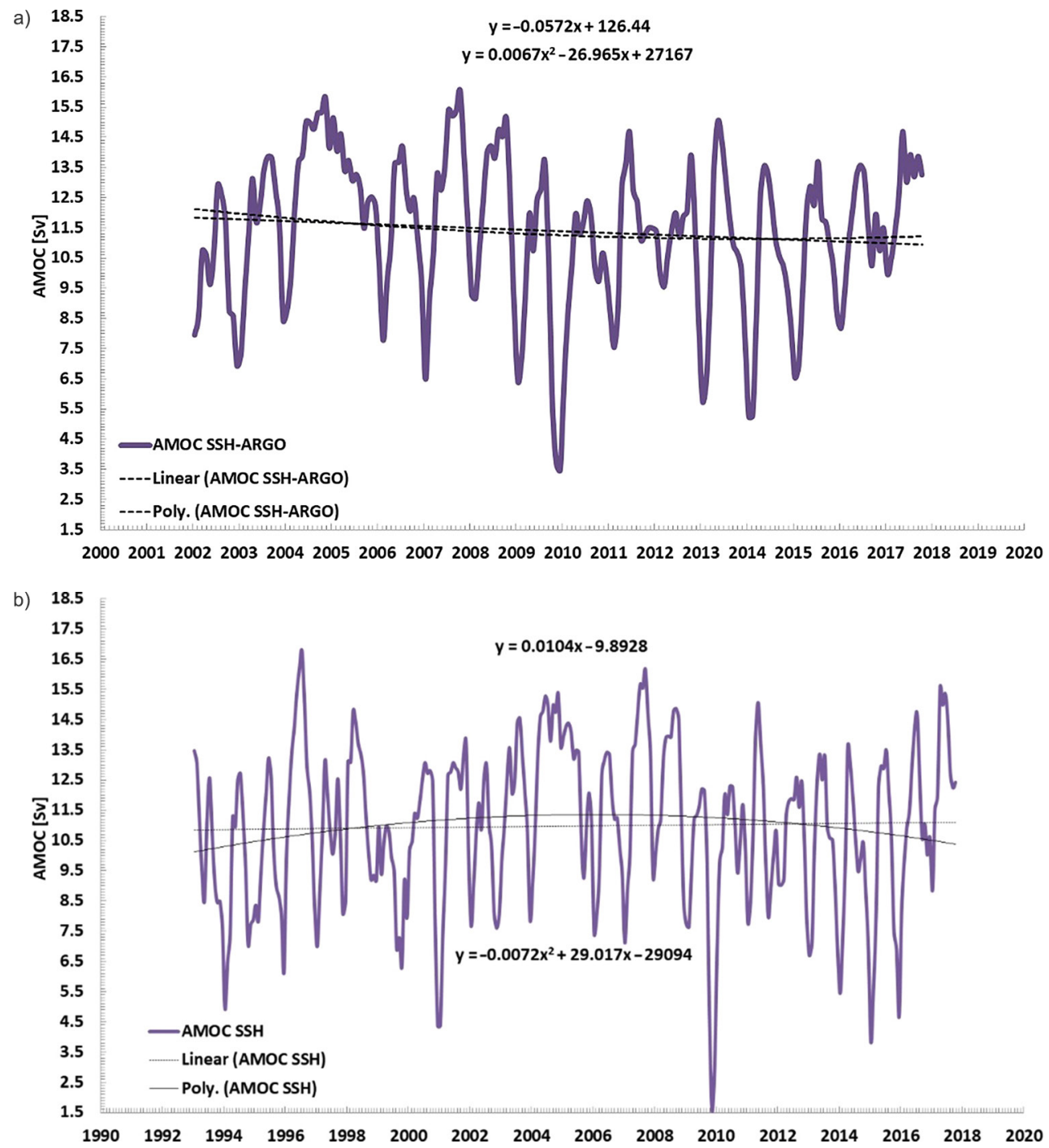

Fig. 2. The Atlantic Meridional Overturning Circulation time series: a) AMOC SSH+ARGO since the year 2002, b) AMOC SSH since the year 1993. The time series represent three-month running averages. 

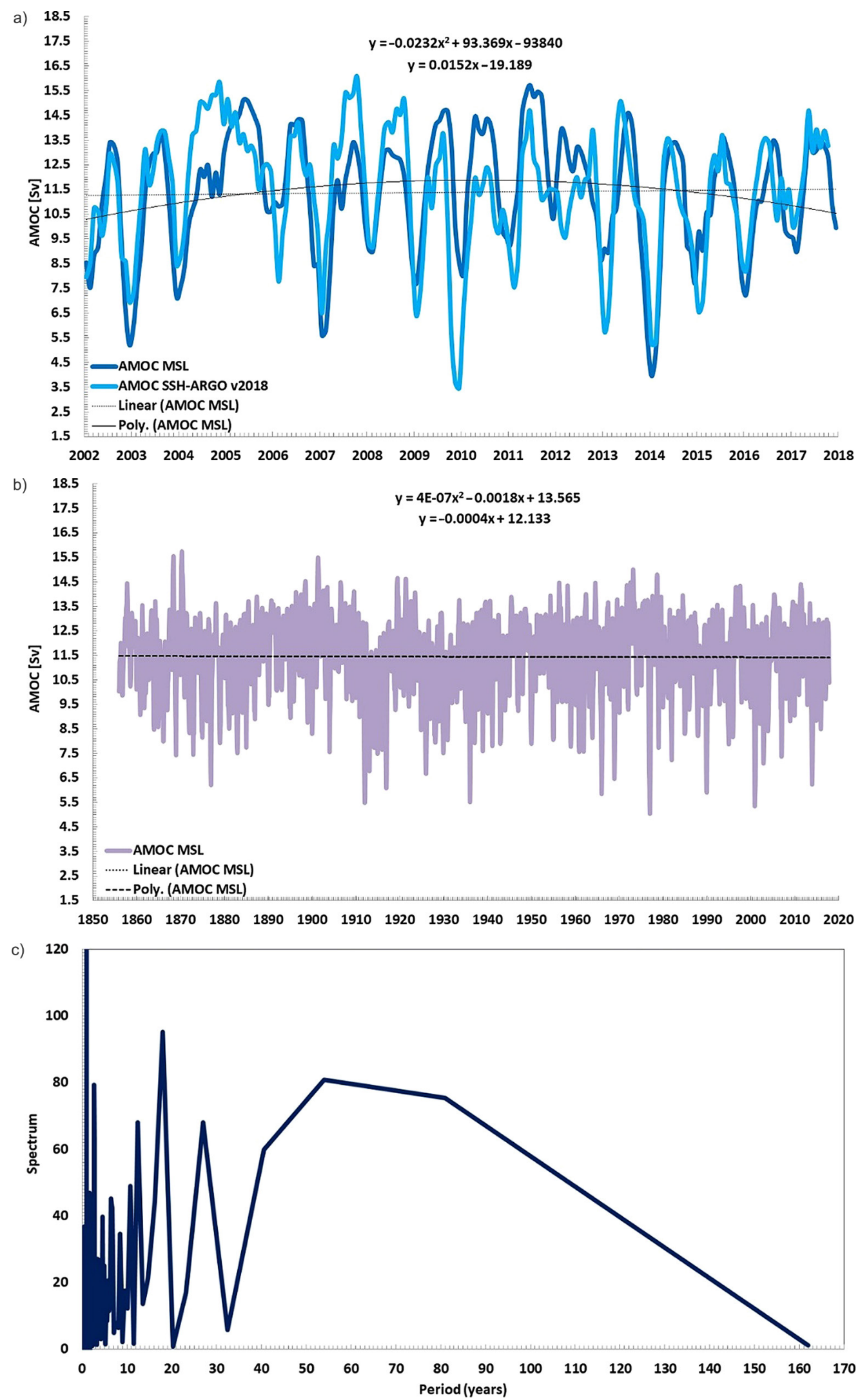

Fig. 3. The Atlantic Meridional Overturning Circulation time series: a) AMOC SSH+ARGO and AMOC MSL since the year 2002 (time series is updated to August 2017), b) AMOC MSL since the year 1856 (time series is updated to December 2017), c) periodogram of the AMOC MSL. The time series represents three-month running averages. 
America (strength reduction) or in an acceleration along the West Coast of Europe (strength increment), then, as the relative sea level acceleration has been small in both locations and very close, and the absolute rate of the sea levels have similarly been about the same in both locations from 1856 to the present, then we should immediately conclude that there has been no change in the AMOC. There has been no sign of sea levels accelerating or rising at differential rates across the Atlantic, demonstrating once more the stability of the sea levels. Therefore, very likely also the AMOC has been only oscillating since the year 1986, the same as the sea levels. Of all the possible AMOC proxies, the sea level is the most reliable. Parker (2016) and Parker and Ollier (2016) proposed a novel proxy AMOC, AMOC MSL, correlated to the difference between the absolute monthly average mean sea levels measured by the tide gauges of The Battery, New York and Brest. This AMOC MSL was linearly related to the AMOC SSH of Willis and Fu (2008), Willis (2010) Hobbs and Willis (2012). Parker (2016) and Parker and Ollier (2016) showed that the trend of this AMOC may be diminishing in a small extent over the short time window, since the early 2000s, but it has been stable since the early 1990s, or even the mid-1800s.

Here we linearly correlate the AMOC MSL to the AMOC SSH+ARGO. Figure 3.a presents the AMOC based on the difference in between the absolute MSL of The Battery, New York and Brest, AMOC MSL, and the AMOC SSH-ARGO since 2002. There is a good correlation between the two AMOCs, both suggesting stability. The AMOC SSH-ARGO is minimally reducing but with a positive acceleration. The AMOC MSL is minimally increasing but with a negative acceleration. Since 2005 , there is an increase of $+0.0152 \mathrm{~Sv} \mathrm{yr}{ }^{-1}$. The acceleration is negative over the time window, $-0.0464 \mathrm{~Sv} \mathrm{yr}^{-2}$, demonstrating the small increment of this AMOC is going to disappear. Figure 3.b presents the AMOC MSL over the longer time window 1856 to present. The trend is negligible, and the acceleration is also negligible. This proxy AMOC, has been incredibly stable since 1856 . It is reducing at a negligible rate of only $-0.0004 \mathrm{~Sv}$ $\mathrm{yr}^{-1}$. subjected to an even more negligible positive acceleration of $+0.0000008 \mathrm{~Sv} \mathrm{yr}^{-2}$. Figure 3.c finally show the result of spectral analysis of the oscillations, the periodogram of this AMOC MSL. The periodogram shows three important decadal and multi-decadal periodicities, of 18 years, 27 years and about 60 years. Hence, very likely the AMOC oscillates with up to a quasi-60 years periodicity like temperatures and sea levels, and apart from natural variability, has not been subjected to any change over the last 150 years.

\section{Conclusions}

Since 2002, the $41^{\circ} \mathrm{N}$ latitude AMOC based on SSH and ARGO ocean temperature, salinity and velocity measurements has been reducing at a rate of only $-0.0572 \mathrm{~Sv} \mathrm{yr}^{-1}$. The acceleration is positive over this time window, $+0.0134 \mathrm{~Sv} \mathrm{yr}^{-2}$, demonstrating the small reduction of this AMOC is going to disappear. Since 1993 , the $41^{\circ} \mathrm{N}$ latitude AMOC based on SSH measurements has been not reducing but increasing, at a rate of $0.0332 \mathrm{~Sv} \mathrm{yr}^{-1}$. The acceleration is now negative over this time window, $-0.0234 \mathrm{~Sv} \mathrm{y^{-2 }}$, demonstrating the small increase of this AMOC is also going to disappear.

Since 1856, the absolute mean sea levels in The Battery, New York and Brest have been rising at about same small rate subjected to about the same small acceleration. The relative sea level accelerations in The Battery, New York and Brest, 1856 to present, have been about the same $+0.00851 \mathrm{~mm} \mathrm{yr}^{-2}$ and $+0.00994 \mathrm{~mm} \mathrm{yr}^{-2}$, respectively. Their difference is smaller than the accuracy of the estimation. The absolute rate of rises of the sea level in The Battery, New York and Brest, from 1856 to the present, have also been about the same, +0.684 to $+0.698 \mathrm{~mm} \mathrm{yr}^{-1}$ and +0.695 to $+0.704 \mathrm{~mm} \mathrm{yr}^{-1}$, respectively. Their difference is smaller than the accuracy of the estimation.

If we accept that the difference between the absolute mean sea levels in The Battery, New York and Brest, that correlates well with the $41^{\circ}$ $\mathrm{N}$ latitude AMOC SSH and AMOC SSH-ARGO, is representative of the AMOC strength, then, this difference has been stable since 1854 . The proposed AMOC mean sea level has not been reducing or increasing, nor accelerating or decelerating, since 1856, but only oscillating with multidecadal periodicities of 18 years, 27 years and about 60 years. Since 1856, the AMOC MSL is reducing at a negligible rate of only $-0.0004 \mathrm{~Sv}$ $\mathrm{yr}^{-1}$ subjected to an even more negligible positive acceleration of $+0.0000008 \mathrm{~Sv} \mathrm{yr}^{-2}$. 


\section{Acknowledgement}

The authors wish to thank Josh Willis for the AMOC data he provided. The authors did not receive any funding and declare no conflict of interests.

\section{Author's contribution}

AP downloaded and analyzed the data. AP and CO discussed the data, and wrote together the manuscript.

\section{References}

Blewitt G., Kreemer C., Hammond W.C., Gazeaux J., 2016. MIDAS robust trend estimator for accurate GPS station velocities without step detection. Journal of Geophysical Research: Solid Earth 121(3): 2054-2068.

Boon J. D., 2012. Evidence of sea level acceleration at U.S. and Canadian tide stations, Atlantic Coast, North America. Journal of Coastal Research 28: 1437-1445.

Caesar L., Rahmstorf S., Robinson A., Feulner G., Saba V., 2018. Observed fingerprint of a weakening Atlantic Ocean overturning circulation. Nature 556(7700): 191.

Chambers D.P., Merrifield M.A., Nerem, R.S., 2012. Is there a 60 -year oscillation in global mean sea level?. Geophysical Research Letters 39(18).

Clark P.U., Pisias N.G., Stocker T.F., Weaver, A.J., 2002. The role of the thermohaline circulation in abrupt climate change. Nature 415(6874): 863.

Cunningham S.A., Kanzow T., Rayner D., Baringer M.O., Johns W.E., Marotzke J., Longworth H.R., Grant E.M., Hirschi J.J.-M., Beal L.M., Meinen C.S., Bryden H.L., 2007. Temporal variability of the Atlantic Meridional Overturning Circulation at $26.5^{\circ} \mathrm{N}$. Science 317 : $935-938$.

Ezer T., Atkinson L.P., Corlett W.B., Blanco J. L., 2013. Gulf Stream's induced sea level rise and variability along the U.S. mid-Atlantic coast. Journal of Geophysical Research 118: 685-697.

Hirschi J., Baehr J., Marotzke J., Stark J., Cunningham S.A., Beismann J.O., 2003. A monitoring design for the Atlantic meridional overturning circulation, Geophysical Research Letters 30(7): 016776.

Hobbs W.R., Willis J.K., 2012. Midlatitude North Atlantic heat transport: A time series based on satellite and drifter data. Journal of Geophysical Research-Oceans 117: C1.

Iyengar R.N., 2009. Monsoon rainfall cycles as depicted in ancient Sanskrit texts, Current Science 97(3): 444-447.

Johns W.E., Baringer M.O., Beal L.M., Cunningham S.A., Kanzow T., Bryden H.L., Hirschi J.J.-M., Marotzke J., Meinen C.S., Shaw B., Curry R., 2011, Continuous, ar- ray-based estimates of Atlantic Ocean heat transport at $26.5^{\circ} \mathrm{N}$. Journal of Climate 24: 2429-2449.

Kuhlbrodt T., Griesel A., Montoya M., Levermann A., Hofmann M., Rahmstorf S., 2007. On the driving processes of the Atlantic meridional overturning circulation. Reviews of Geophysics 45(2).

Levermann A., Griesel A., Hofmann M., Montoya M., Rahmstorf S., 2005. Dynamic sea level changes following changes in the thermohaline circulation. Climate Dynamics 24(4): 347-354.

Lozier M.S., Roussenov V., Reed M.C.S., Williams R.G., 2010. Opposing decadal changes for the North Atlantic meridional overturning circulation, Nature Geoscience 3: 728-734

NGL [Nevada Geodetic Laboratory], 2018. The Nevada Geodetic Laboratory - Velocities. Online: geodesy.unr.edu/ velocities/midas.IGS08.txt (accessed December 7, 2018).

NGL [Nevada Geodetic Laboratory], 2019. The Nevada Geodetic Laboratory. Online: geodesy.unr.edu (accessed February 13, 2019).

Parker A., 2013. Oscillations of sea level rise along the Atlantic coast of North America north of Cape Hatteras. Natural Hazards 65(1): 991-997.

Parker A., 2016. Atlantic Meridional Overturning Circulation is stable under global warming. Proceedings of the National Academy of Sciences 113(20): 2760-2761.

Parker A., Ollier C.D., 2016. There is no real evidence for a diminishing trend of the Atlantic Meridional Overturning Circulation. Journal of Ocean Science and Technology 1(1): 30-35.

PSML [Permanent Service for Mean Sea Level], 2019. Permanent Service for Mean Sea Level. Online: www.psmsl.org (accessed February 13, 2019).

Sallenger A.H., Doran K.S., Howd P.A., 2012. Hotspot of accelerated sea-level rise on the Atlantic coast of North America. Nature Climate Change 2: 884-888.

Schlesinger M.E., Ramankutty N., 1994, An oscillation in the global climate system of period 65-70 years. Nature 367: 723-726.

The RAPID project, 2019. RAPID-AMOC - Monitoring the Atlantic Meridional Overturning Circulation. Online: www.rapid.ac.uk (accessed February 13, 2019).

Thornalley D.J., Oppo D.W., Ortega P., Robson J.I., Brierley C.M., Davis R., Hall I.R., Moffa-Sanchez P., Rose N.L., Spooner P.T., Yashayaev I., 2018. Anomalously weak Labrador Sea convection and Atlantic overturning during the past 150 years. Nature 556(7700): 227.

Willis J.K., 2010. Can in situ floats and satellite altimeters detect long-term changes in Atlantic Ocean overturning?, Geophysical Research Letters 37: L06602.

Willis J.K., Fu L.-L., 2008. Combining altimeter and subsurface float data to estimate the time-averaged circulation in the upper ocean. Journal of Geophysical Research 113: C12017.

Yin J., Schlesinger M.E., Stouffer R.J., 2009. Model projections of rapid sea-level rise on the northeast coast of the United States. Nature Geoscience 2: 262-266. 
Appendix 1. Subsidence of the NYBP and BRST GPS antenna nearby the tide gauges

The GPS time series for NYBP, nearby the tide gauge of The Battery, New York, and BRST, near the tide gauge of Brest. The MIDAS velocity fields in IGS08 reference frame suggest a subsidence velocity of $-2.150 \pm 0.973 \mathrm{~mm} \mathrm{yr}^{-1}$ based on data 2009.3087 to 2018.6475 in NYBP, and a subsidence velocity of $-0.638 \pm 0.668 \mathrm{~mm} \mathrm{yr}^{-1}$ based on data 1998.8309 to 2018.6475 in BRST.
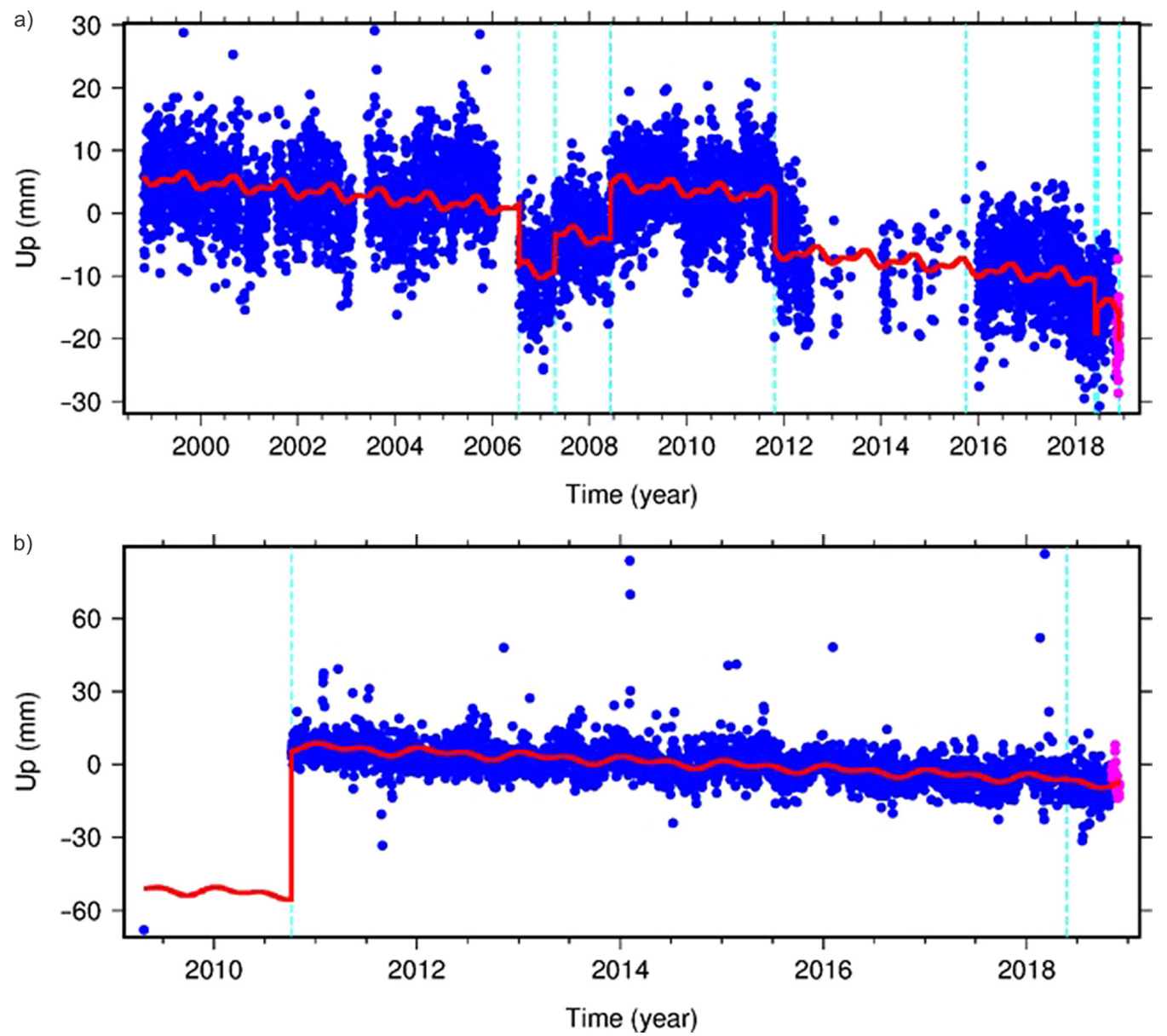

Fig. A.1.1. GPS position time series for the GPS antenna near the tide gauges of a) The Battery, New York and b) Brest. Images reproduced and modified after geodesy.unr.edu. 
Appendix 2. Stability of the AMOC SSH+ARGO and AMOC SSH data sets

A comparison of the AMOC SSH+ARGO and AMOC SSH data sets of 2015 and 2018. The differences reflect changes in the data sets used in the computations. Most of the data sets of climate parameters are unfortunately subjected to continuous revisions of the past values.
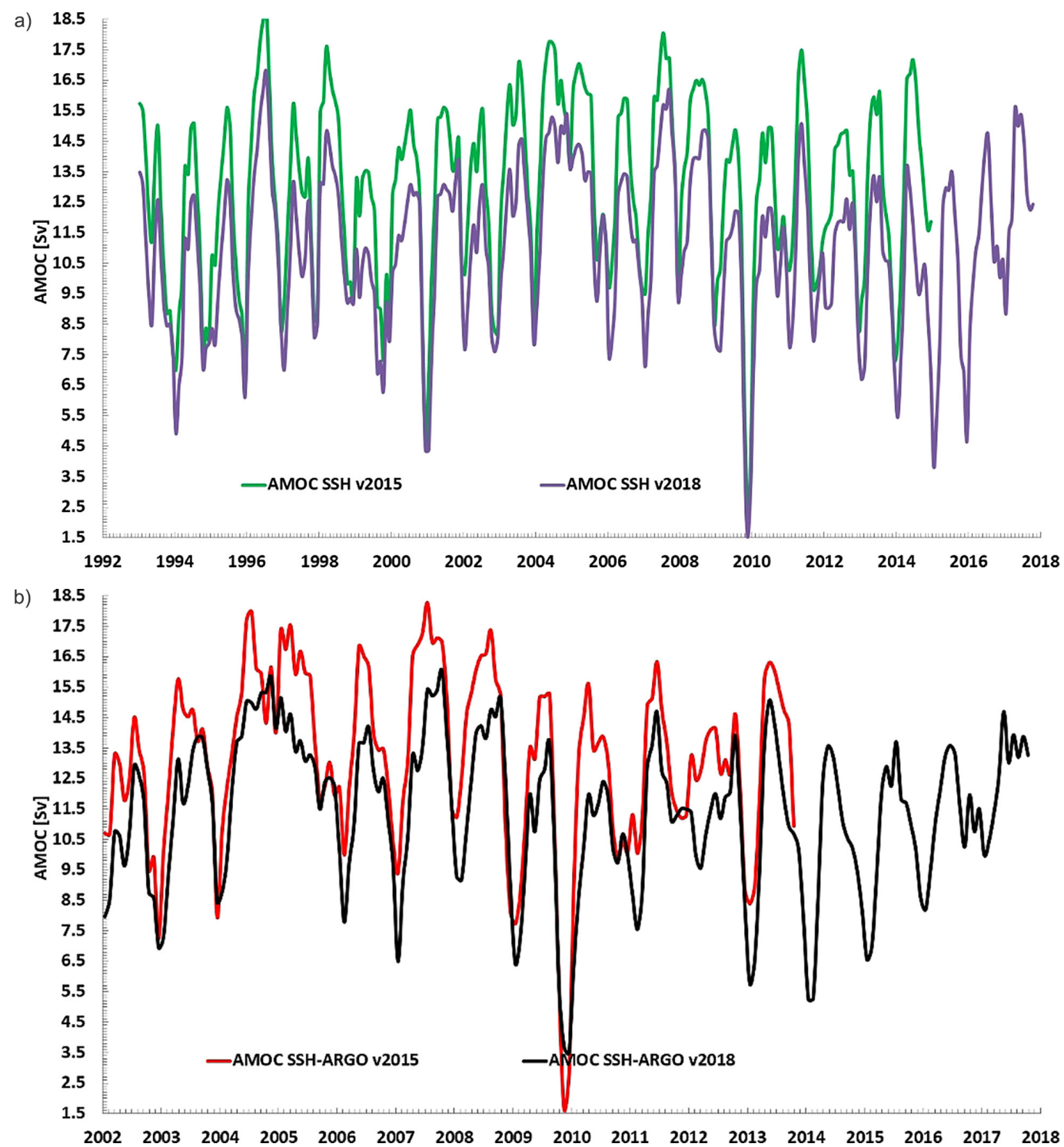

Fig. A.2.1. Comparison of the AMOC SSH (a) and AMOC SSH+ARGO (b) of 2015 and 2018. 